\title{
EVALUATION OF SEISMIC RESPONSE OF STRUCTURAL SYSTEMS IN HIGH.RISE BUILDING WITH DIFFERENT CONFIGARATION USING ETABS
}

\author{
Anitha Ganesh Shetty ${ }^{1}$, G Narayan ${ }^{2}$ \\ ${ }^{1}$ M.Tech student, Dept of civil Engineering, SJCIT, Chickballapura, Karnataka, India \\ ${ }^{2}$ Professor \& HOD, Dept of civil Engineering, SJCIT, Chickballapura, Karnataka, India
}

\begin{abstract}
The imperative of tall structure have been rapidly growing far and wide. However, one of the regular wonder which is delivered in earth covering that is shake. Length of seismic tremor within couple of minutes an enormous number of people lose their lives and structures in different parts of the world. Starting late structures are ending up being progressively thin and exposed to impact and along these lines hazardous in the midst of tremor, parallel unfaltering quality has reliably been a critical issue of structures especially in the reaches with high shake peril. Exactly when a tall building is subjected to parallel or torsional redirection under action of fluctuating sidelong loads, the consequent oscillatory advancement can incite a broad assortment of response in the building tenants from the smooth uneasiness to serious affliction. Hence flat robustness is genuine thought in the diagram of tall structures. In the present research we have used software ETABS as per Indian standards. The comparison has been carried out for 20-storey, 40-storey, 60-storey of (i) Bracing system (ii)Frame with shear band and outrigger trusses system (iii)Outtrigger system (iv)Diagrid systems and combinations in (v) Bracing and outtrigger system (vi)Out trigger and Diagrid system (vii) Diagrid and frame with shear band and outtrigger trusses (viii) Bare frame are studied here. The modelling are done to examine the effect of different cases along with different heights on seismic parameters like base shear, lateral displacement, lateral drifts. The study has been carried out for zone v. Static and dynamic methods are used to analyses the structural systems.
\end{abstract}

Keywords: structural systems, lateral displacement, storey drift, base shear

\section{INTROUCTION}

This from mechanical headway development in basic system structures are getting to be taller and taller. Because of structures statures prompting the likelihood of more influence. So for structural designers this has purchased more difficulties to deal with working from both gravity loads furthermore sidelong loads. In investigation seismic zone element assumes a fundamental part in the seismic safe outline of structures since it relies on upon seismic force and another essential perspective in the configuration is soil sort. Structural systems are great in horizontal burden opposing systems. In structural systems, exchanges loads through which are associated with each other in an effective way associated basic parts. Each one now a day's tending to utilize tall steel structures as a result of effective, prudent, quality, steadiness, flexibility, simplicity of raising are significant motivation behind seismic configuration

\subsection{High Rise Building}

From the earliest starting point of the progress people are more focused on elevated structures and design sees if structures. The tall structures relies on upon people groups subsequent recognitions, so for this there is no accurate definition.

As indicated by chamber of tall structures congress Toronto, Canada elevated structure is "a building whose stature makes diverse outline conditions and developments and use than those that exist in like manner structures of certain locale and period". However, from basic specialists perspective "a building stature is above $23 \mathrm{~m}$ to $150 \mathrm{~m}$ and it get influenced by horizontal powers".

\section{MODEL DESCRIPTION}

\begin{tabular}{|c|c|}
\hline $\begin{array}{ll}\cdot & \text { Type of structure } \\
\cdot & \text { Plan dimension } \\
\cdot & \text { Number of bays } \\
\cdot & \text { Thickness of slab } \\
\cdot & \text { Typical storey } \\
\text { height } & \\
\cdot & \text { Grade of concrete } \\
\cdot & \text { Grade of } \\
\text { structural steel } \\
\cdot & \text { Beam size } \\
\cdot & \text { Column size } \\
\cdot & \text { Bracing size } \\
\cdot & \text { Storey } \\
\cdot & \text { Floor finish } \\
\cdot & \text { Wall load } \\
\cdot & \text { Zone } \\
\cdot & \text { Soil type }\end{array}$ & $\begin{array}{l}150 \mathrm{~mm} \\
3 \mathrm{~m} \\
M 35 \\
\text { Fe } 345 \\
I S M B 500 \\
I S W B 450-2 \\
200 X 200 X 25 \mathrm{~mm} \\
20,40,60 \\
1.5 \mathrm{KN} / \mathrm{m}^{2} \\
10 \mathrm{KN} / \mathrm{m} \\
V \\
l l\end{array}$ \\
\hline
\end{tabular}


Different types of module shown in below:

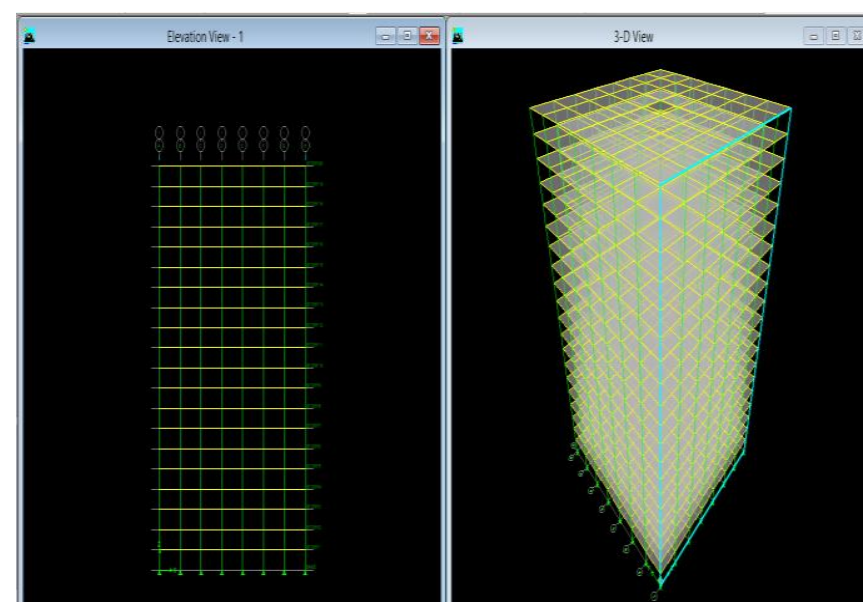

Fig-1 Bare frame model

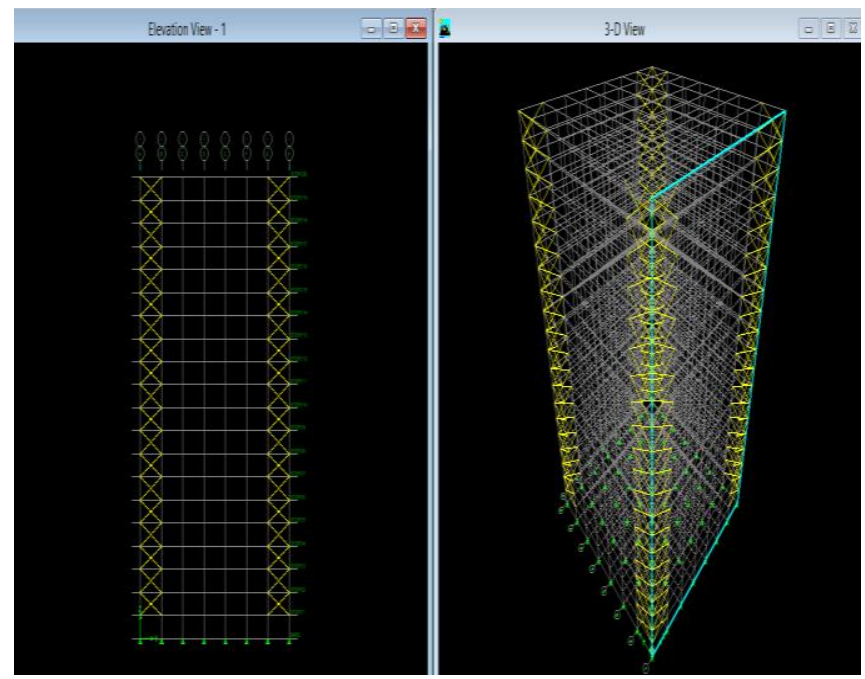

Fig-2 Bracing systems model

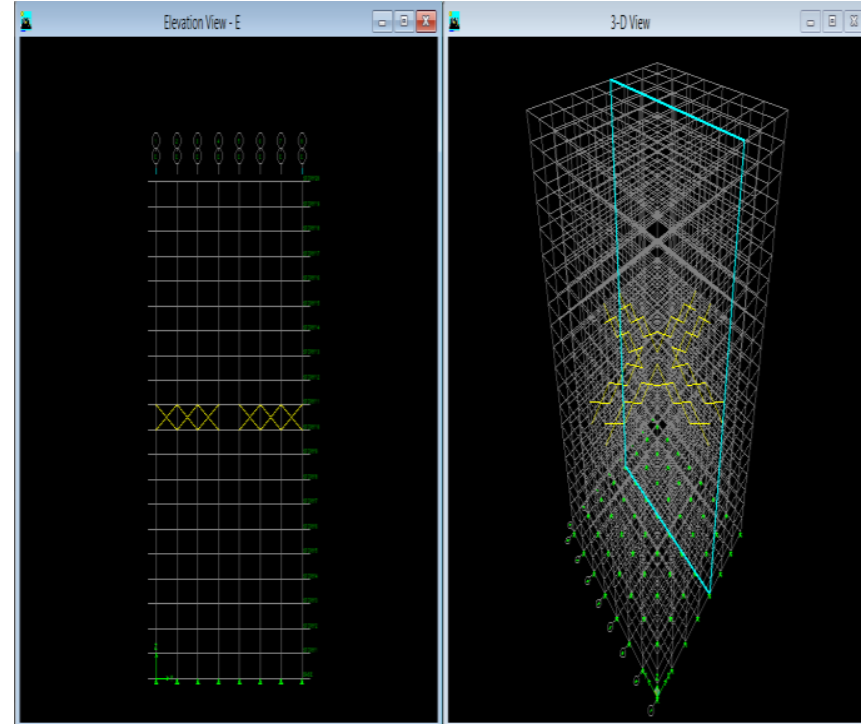

Fig-.3 Outrigger system model

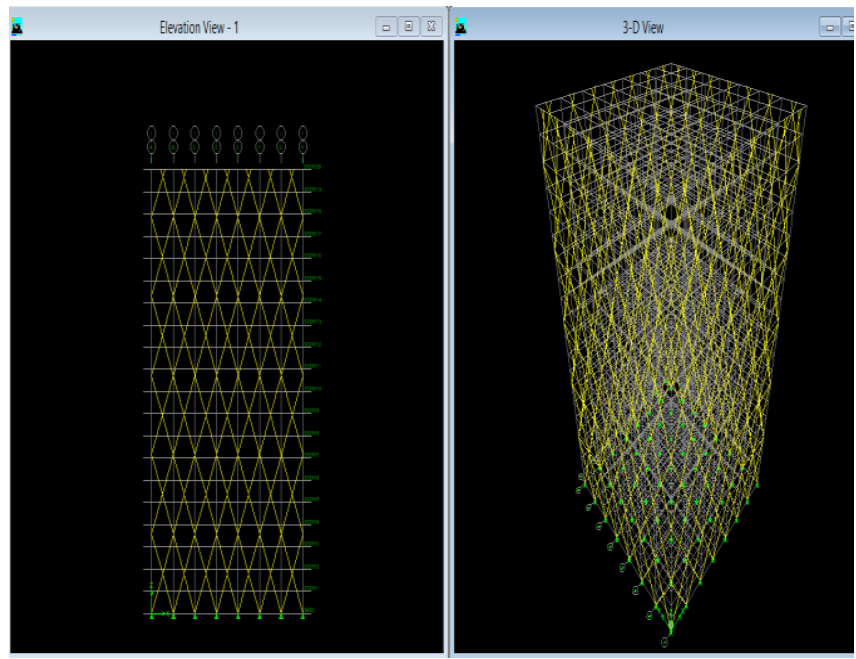

Fig-4 Diagrid system model

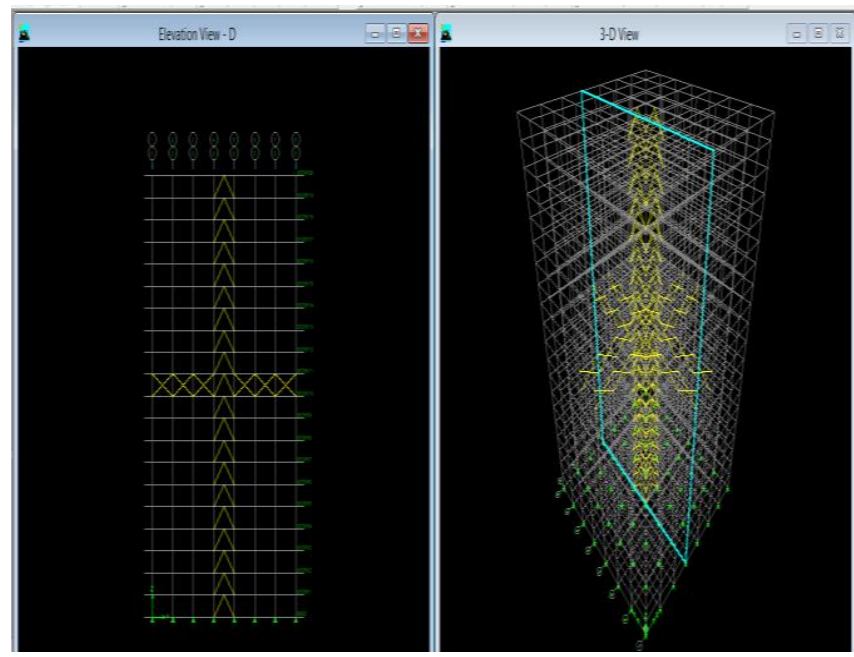

Fig-5 Outrigger with shear band system model

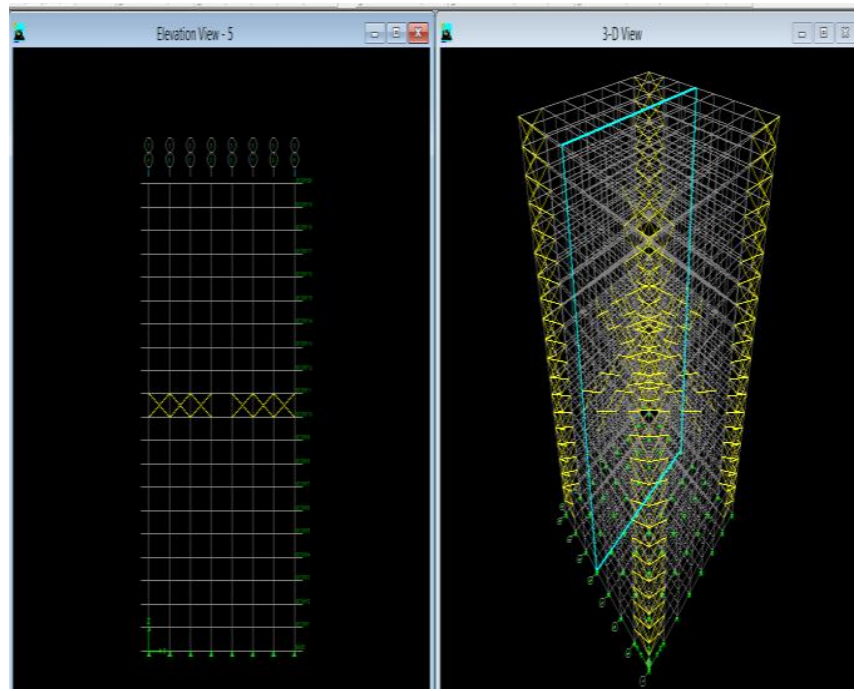

Fig-6 Bracing with Outrigger system 


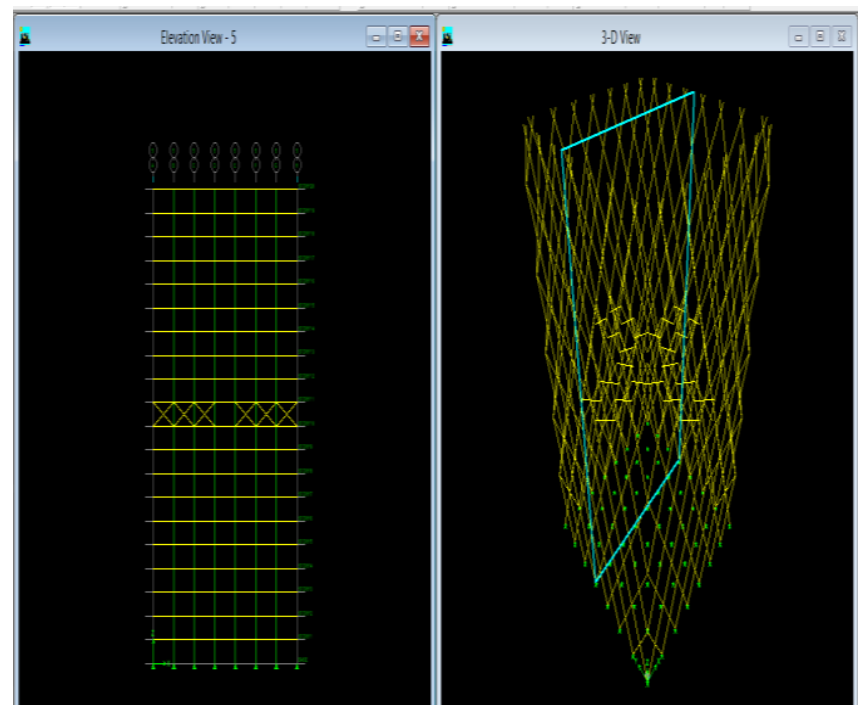

Fig-7 Outrigger with Diagrid system model

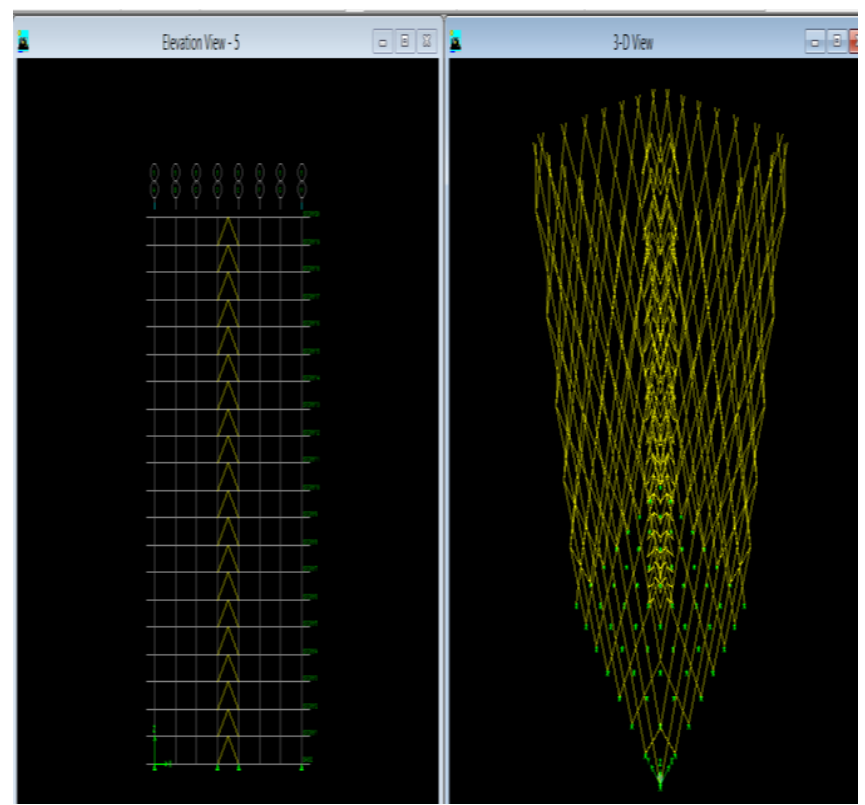

Fig-8 Diagrid with Shear band system model

Here are the mathematical models which are modelled with 20, 40, 60 storey.

Type 1- Bare frame

Type 2- Bracing system

Type 3-Outrigger system

Type 4-Diagrid system

Type 5- Outrigger system with shear band

Combination 1- Bracing with Outrigger system

Combination 2- Outrigger with Diagrid system

Combination 3- Diagrid with Outrigger system with shear band

\section{RESULTS}

\subsection{Lateral Displacement Results}

\section{Lateral displcement v/ Storey- Static method}

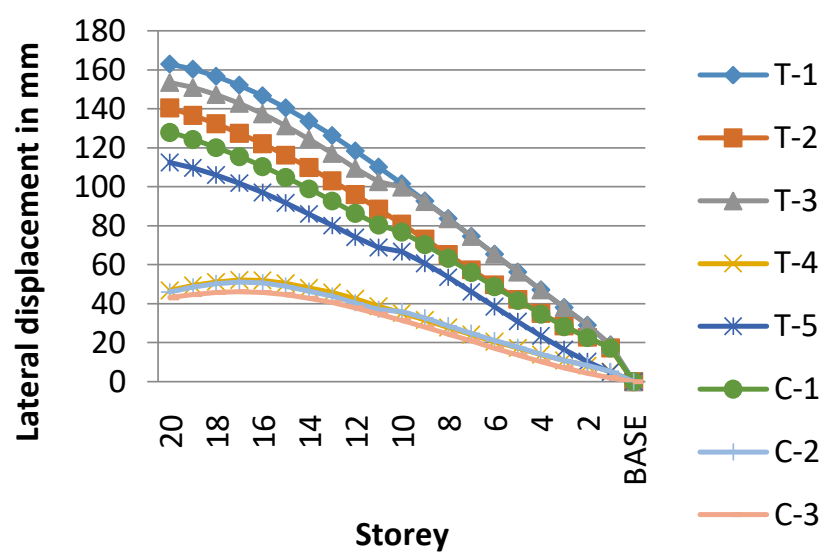

Fig. 9 Displacements values for 20 storey from static method

\section{Lateral displacements v/s Storey- Dynamic method}

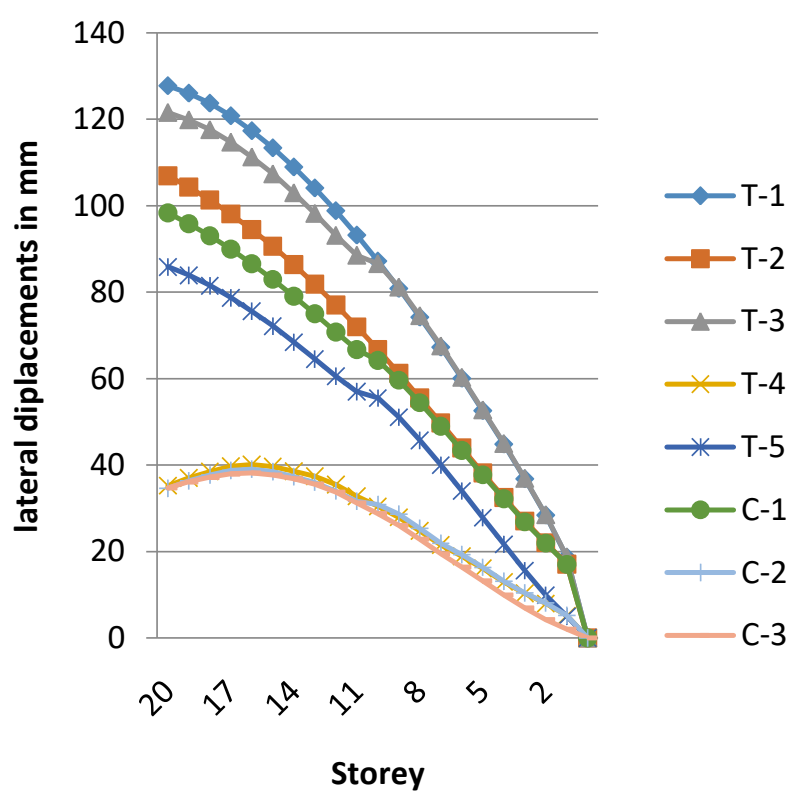

Fig. 10 Displacements values for 20 storey from dynamic method 
Lateral displacements v/s StoreyStatic method

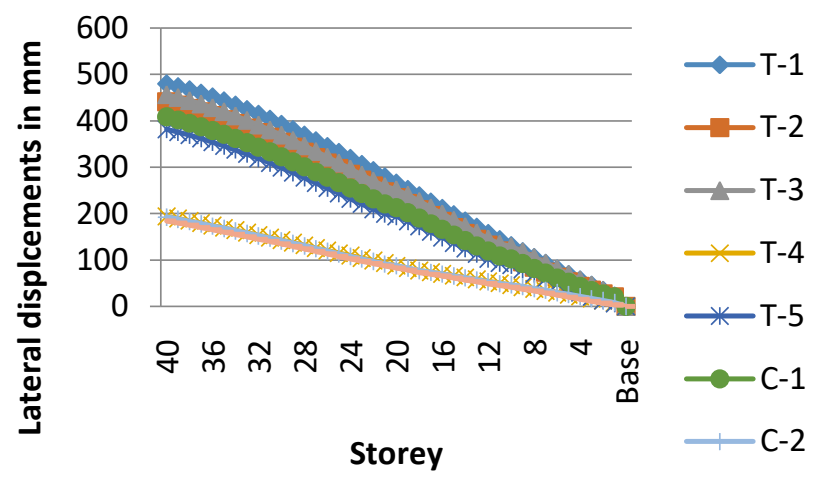

Fig. 11 Displacements values for 40 storey from static method

\section{Lateral displacements v/s Storey-} Dynamic method

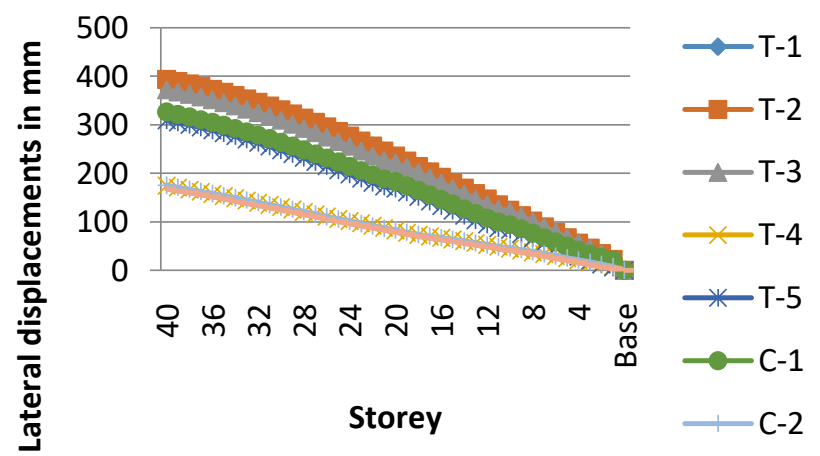

Fig.12 Displacements values for 40 storey from dynamic method

\section{Lateral displacements $\mathrm{v} / \mathrm{s}$ Storey-Static method}
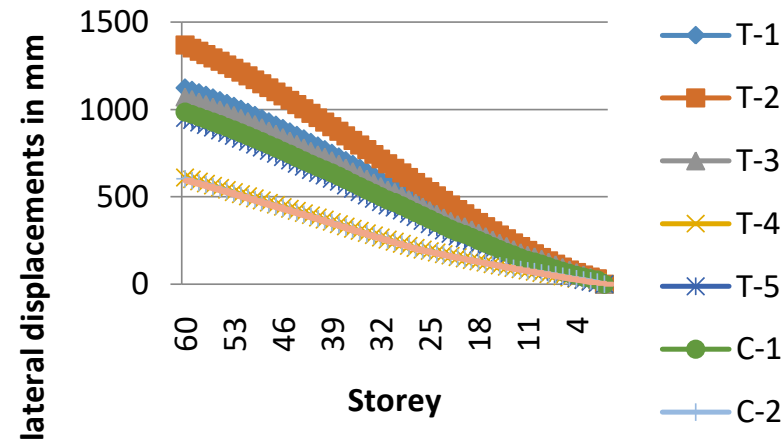

Fig.13 Displacements values for 60 storey from static method

\section{Lateral displacements $\mathrm{v} / \mathrm{s}$ storey-Dynamic method}

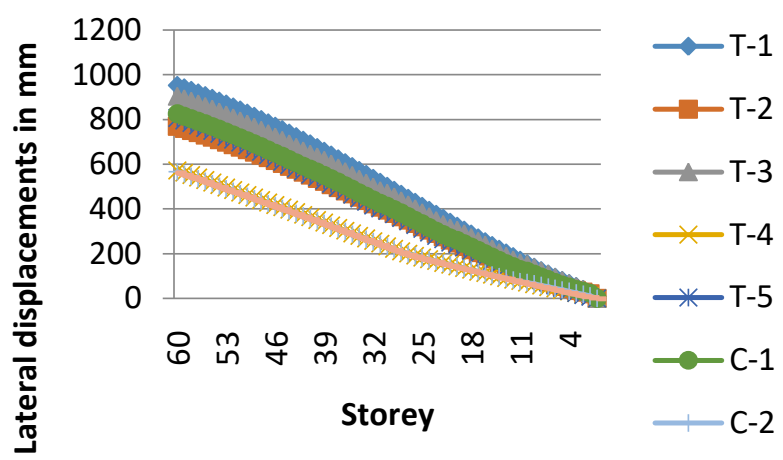

Fig.14 Displacements values for 60 storey from dynamic method

* Lateral displacement values with storey results concluded here:

- Height increases gradually lateral displacements value also increases.20 storey result as datum(160mm), $68 \%$ for $40,88.57 \%$ for 60 storey.

- Dynamic values lesser than static values in all storey cases almost $12.5 \%, 16.6 \%, 28.57 \%$ in 20,40,60 storey building.

- The displacements values lesser in c1,c2,c3 types, it is almost $75 \%, 60 \%, 57 \%$ lesser value then the bare frame.

- Diagrid with shear band combination system gives least lateral displacement results

\subsection{Storey Drifts Results}

\section{Storey drift v/s Storey-Static method}

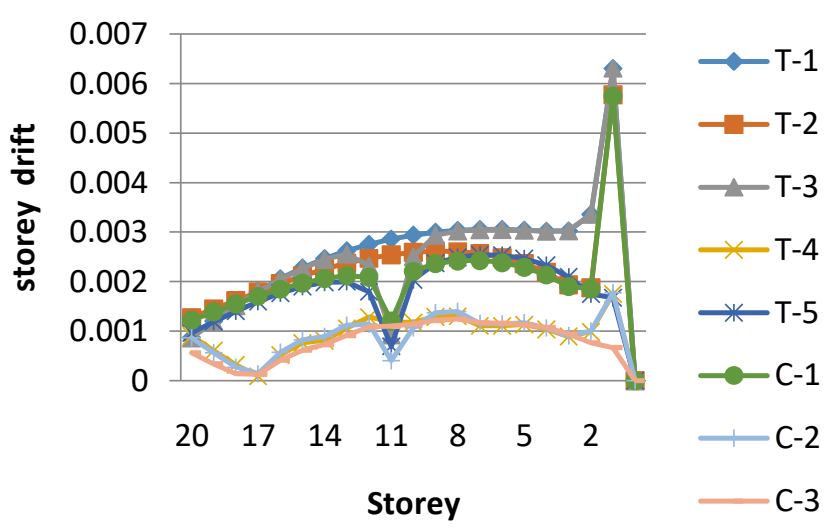

Fig.15 Storey drifts values for 20 storey from static method 


\section{Storey drift v/s Storey-Dynamic method}

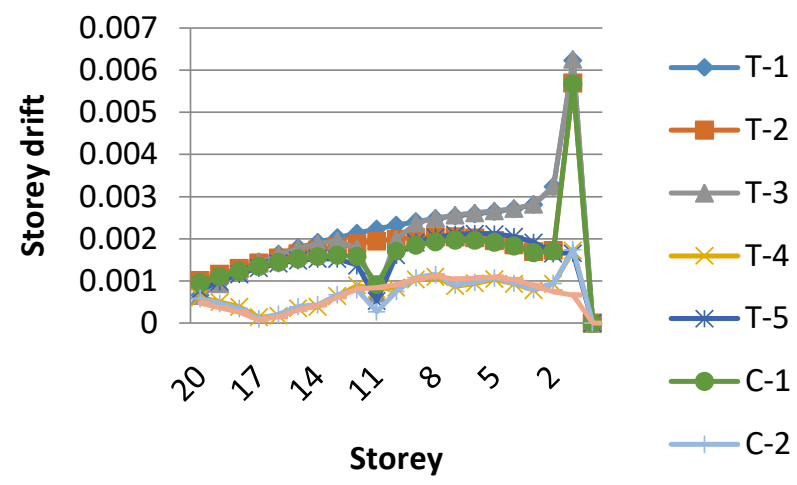

Fig.16 Storey drifts values for 20 dynamic from dynamic method

\section{Storey drift v/s Storey - Static method}

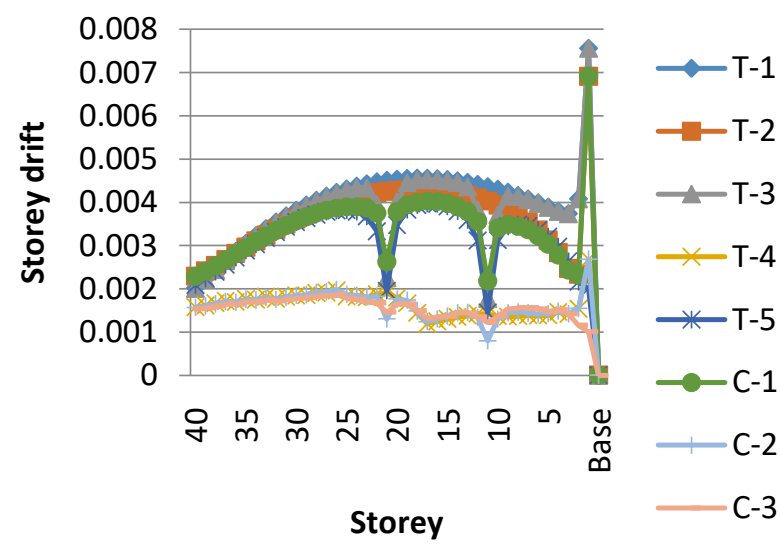

Fig.17 Storey drifts values for 40 storey from static method

\section{Storey drift v/s Storey-Dynamic method}

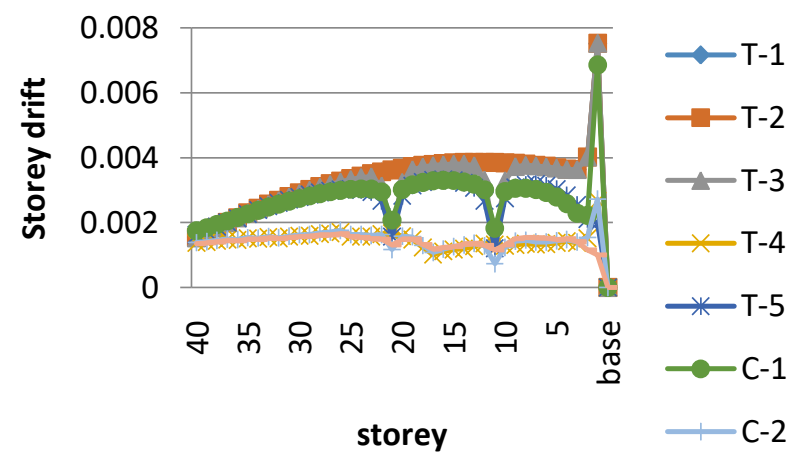

Fig.18 Storey drifts values for 40 storey from dynamic method

\section{Storey drift v/s Storey -Static method}

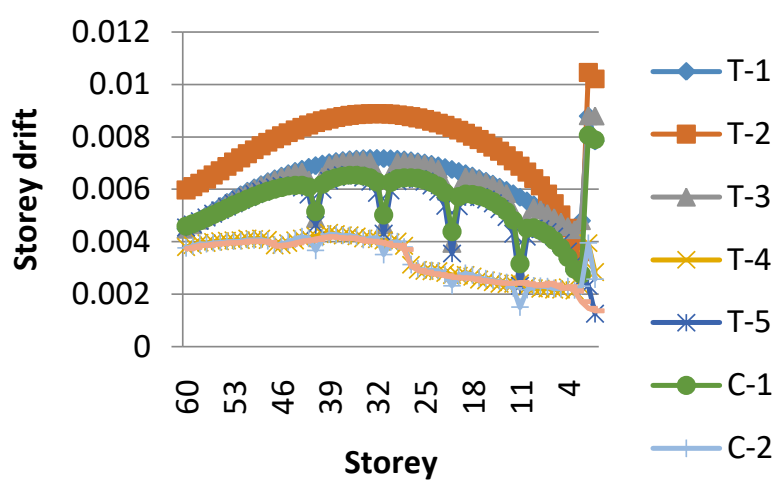

Fig.19 Storey drifts values for 60 storey from static method

\section{Storey drift v/s Storey - Dyanmic method}

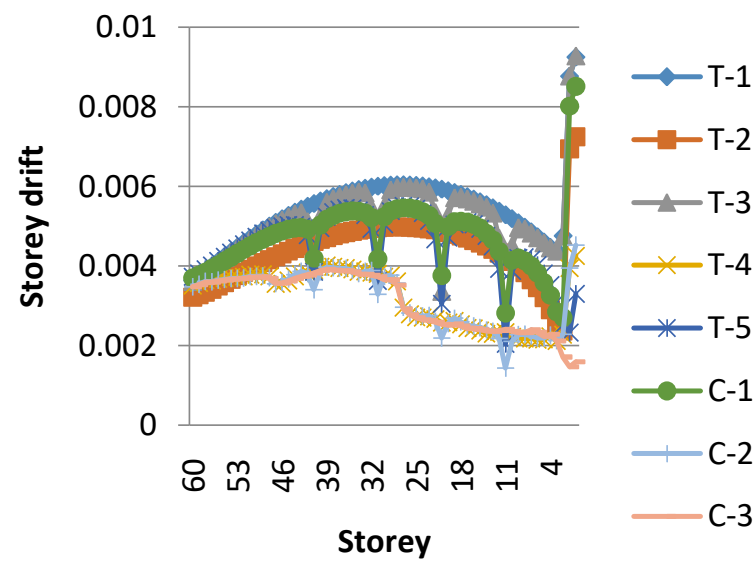

Fig.20 Storey drifts values for 60 storey from dynamic method

- Storey drift values with storey results concluded here:

- Height increases gradually storey drift value also increases.20 storey result as datum( 0.006$), 14 \%$ for $40 \%$ for 60 storey.

- The storey drift values lesser in c1,c2,c3 types, it is almost $80 \%, 78 \%, 75.6 \%$ lesser value then the bare frame.

- In all storey cases outrigger with shear band system given lesser value compared to others.

- Wherever shear band is used in that floor suddenly drift values reduced (75\%) except T1, T2,T4, T5 and $\mathrm{C} 3$.

- Outrigger and its combination systems gives less drift values. 


\subsection{Base Shear Values Results}

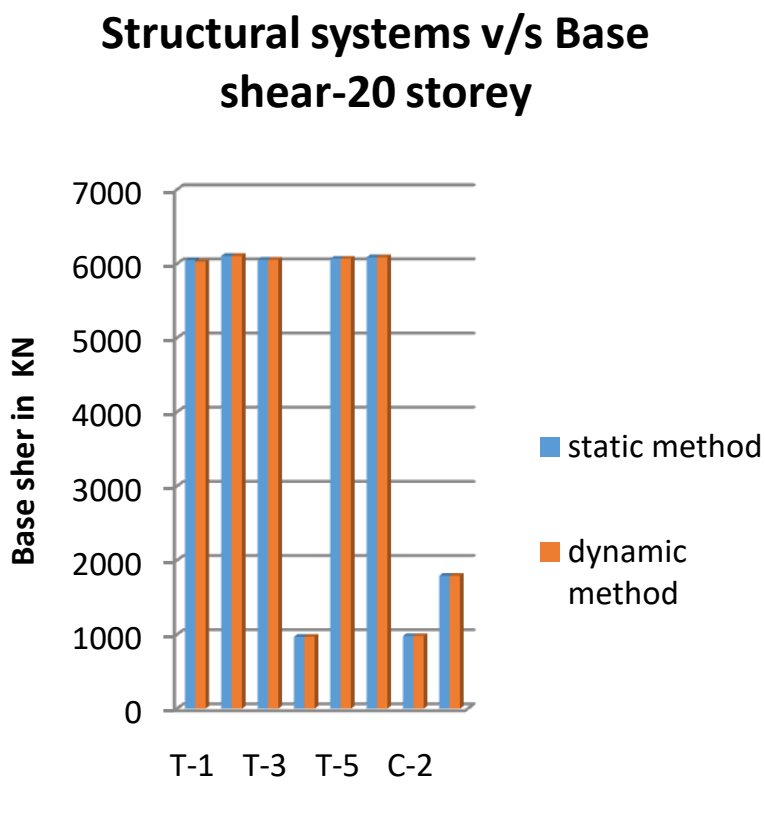

Types of structural systems

Fig.21 Base shear values for 20 storey

\section{Structural systems v/s Base shear-40 storey}

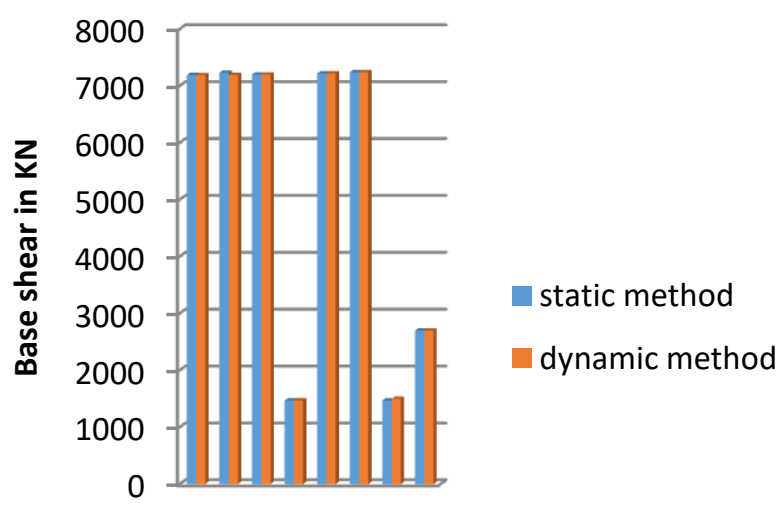

T-1 T-3 T-5 C-2

Types of structural systems

Fig.22 Base shear values for 40 storey

\section{Structural systems v/s Base shear -60 storey}

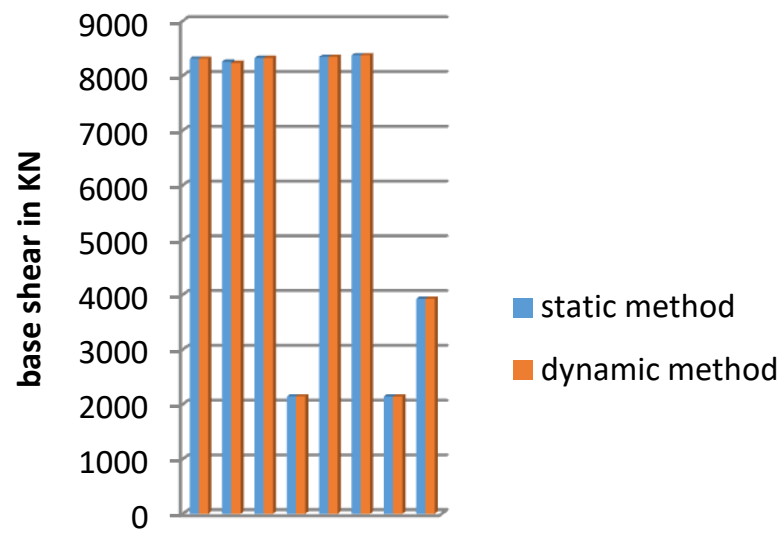

12345678

Types of strucural systems

Fig.23 Base shear values for 60 storey

Base shear values with storey results concluded here:

- In all static and dynamic method results for all types got almost same values here height increases, values increases.

- In this graph for T1, T2, T3, T5 and T6 values higher than T4, T7, T8 values. In all storey outrigger system got least values for base shear results.

- Here concluded that outrigger system and its combination gives positive results for less base shear.

- For T4 systems gives almost $85 \%$ lesser values than other systems.

\section{CONCLUSION}

- As per above results, the building tallness expands story drift furthermore lateral displacement steadily increases.

- Diagrid with shear band combination system gives least lateral displacement results.

- One of the most imperative conclusions that can be produced using above study that, which floor, outrigger combination utilized as a part of that floor, story drift values decreased.

- The outtrigger with shear band structural system and its combinations not just effective in controlling the lateral displacements likewise decreasing the story drifts.

- Outrigger system and its combinations and C3 type story drift results are closer contrasted with different systems.

- As per story drift graphs, values more in first floor than bit by bit diminishes aside from T4, T5, C2 ,C3 sort results.

- Number of story builds base shear values likewise increments. 
- Analyzing the base shear diagrams outrigger system comes about verging on diminished $85 \%$ contrasted with other system results.

- After T4, C2 and C3 are having lesser base shear esteem.

\section{ACKNOWLEDGEMENT}

First and foremost, praise and thanks goes to my God and Parents for the blessing that has bestowed upon me in all my endeavors. I am deeply indebted to Dr. G Narayan, Professor \& HOD of Structural Engineering Division, my advisor and guide, for the motivation, guidance, tutelage and patience throughout the project work. I appreciate his broad range of expertise and attention to detail, as well as the constant encouragement he has given me over the years.

\section{REFERENCES}

[1] Abhijeet Baikerikar, Kanchan Kanagali, "Study Of Lateral Load Resisting System Of Variable Heights In All Soil Types Of High Seismic Zone". IJRET, volume-03, Issue-10,oct-2014,Eissn:23191163,Pg 109-119.

[2] Er. Nishant Rana, Siddhant Rana, "Structural Forms Systems For Tall Building Structures" SSRG-IJCE, volume-01, Issue-04, Sept-2014, ISSN:23488352,Pg-8355.

[3] H. Sheikh and A. Massumi, "Effects Of Bracing Configuration On Seismic Behavior Of Tall Steel Structures Subjected To Earthquake Ground Motion's" 10NCEE, July 21-25,2014.

[4] Amolv. Gowardhan, Prof.G.D.Dhawale, Prof.N.P.Shende, "A Review On Comparative Seismic Analyziz Of Steel Frame With And Without Bracing By Using Software." IJERO, volume-03, Issue-11, April-2015, ISSN:7758, Pg219-225.

[5] Y.U.Kulkarni, Prof.P.K.Joshi, “Analysis And Design Of Various Bracing System In High Rise Steel Structures", IJARSE, volume-03, Issue-11, Nov2014, ISSN-2319-8354(E), Pg 11-17.

[6] Mohamed Fadil Kholo Mokin, R.K. Pandey,Prabhatkumarsinha, "Performance Of Lateral Systems In Tall Buildings For Varying Soil Types", IJCIET, volume-05, Issue-03, March-2014, ISSN 0976-6316, Pg 15-22.

[7] Adithya.M, Swathirani.K.S, Shruthi.H.K, Dr.Ramesh.B.R, "Study On Effective Bracing Systems For High Rise Steel Structures", SSRGIJCE, volume-02, Issue-02, Feb-2015, ISSN: 23488352, Pg 19-25.

[8] Z.A.Siddizi, Rashid Hameed, Usman Akmal, "Comparison Of Different Bracing Systems For Tall Buildings" Pak.J.Engg\& Appl.Sci,volume-14, Jan2014, Pg-17-26.

\section{BIOGRAPHIES}

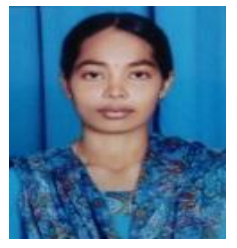

I am Anitha Ganesh Shetty, student , structural engineering, civil department, SJC Institute of Technology, Chickballapura

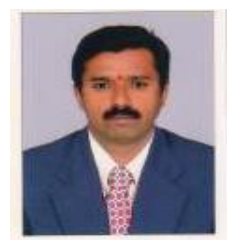

He Mr. Dr. G Narayana, Professor and Head of Department, Department Of Civil Engineering, S J C Institute of Technology, Chickballapura. He has a wide experience in teaching and research in the field of Structural engineering. He is also a structural designed consultant for many project. 